\title{
Evolución de la Sociología. Futuro e historia
}

\author{
Pablo de Jesús Castro $\mathrm{H}$. \\ Profesor Emérito, Sociólogo \\ pdjcash@hotmail.com
}

\section{Resumen}

Esta síntesis pretende describir elementos muy generales sobre su origen histórico, desarrollo y futura proyección. En tres apartados destacamos: 1) Surgimiento de élites intelectuales que dieron origen a la sociologíaCCSS clásica, que dejaron herencia a generaciones contemporáneas. 2) Creación de su objeto de estudio con base en un sistema conceptual y categorial constructor de teorías, métodos, prácticas sociales y académicas. 3) Destacar innovadores procesos de investigación científica productores de conocimientos y pensamiento sociológico que cualifican su status de ciencia social abierta a las necesidades y realidades del presente-futuro.

Palabras claves: Sociología, historia, economía, política, capital social, capital económico, tradición, antropología, religión.

\begin{abstract}
This synthesis aims to describe very general elements on its historical origins, evolution and future projection. There are three main entries: the arise of the intellectual elites on which the classical social sciences-sociology arose, leaving a heritage to the contemporary generations 2- the creation of its object of study based on a system of concepts and categories that build theories, methods, and social as well as academic practices. 3- to pinpoint innovative processes of scientific research which produce a sociological knowledge and thought therefore qualifying is status as a social science open to the needs and realities of this present-future.
\end{abstract}

Key words: Sociology, history, economics, politics, social capital, economic capital, tradition, anthropology, religion.

"Todos los principios de siglo tienen algo de lo primigenio y de un recomenzar radical. Las CCSS del siglo XXI están por hacerse" (Scribano, 2015: P. 422). 


\section{Primera parte}

"Una ciencia que vacila en olvidar a sus fundadores está perdida" (Alfred N. White Head). "Más, para olvidar algo, primero hay que conocerlo. Una ciencia ignorante de sus fundadores no sabe cuánto camino lleva recorrido, ni en qué dirección, también está perdida" (Alvin Gouldner).

\section{Sociedad y sociología en la era de la industrialización capitalista. Siglos XVIII y XIX}

\section{Contexto histórico en la sociedad europea. Situación social, política y económica}

En la era de la ilustración e iluminismo, la Revolución francesa (1789-1819), la independencia de la nueva nación de Estados Unidos (1776) y la era del maquinismo o Revolución industrial inglesa (1760-1830), la sociedad que se construía posibilitó la formaron de élites intelectuales entre filósofos, políticos, economistas, educadores, lingüistas y otros, intentando explicar los nuevos fenómenos de impacto humano y social; así lo hacían biólogos, alquimistas, físicos, matemáticos, astrónomos y otros, quienes crearon su propio método científico experimental (con criterio más cuantitativo que cualitativo) explicativo de fenómenos de la naturaleza física y del universo. A este método se adscribieron inicialmente las ciencias sociales, en especial la Sociología, contribuyendo a la construcción de su objeto de estudio. Otros intelectuales se inclinaron a los aportes religiosos, artísticos y humanistas.

Algunas de sus ideas provenían de raíces ancestrales de la civilización griega del Renacimiento (saberes del romanticismo, arte, literatura, ciencia, tecnología...). Con una nueva racionalidad del pensamiento, fusionaron y articularon conocimientos innovadores alrededor de esos fenómenos y produjeron la revolución científica y tecnológica como soporte de la industrialización moderna. In situ observaron y analizaron que el capitalismo industrial liberal convertía en escombros viejas estructuras sociales, humanas y naturales de la sociedad feudal europea. Cambiaba y transformaba sus relaciones sociales y de producción de comunidades primitivas y antiguas por otras nuevas relaciones económicas, sociales, políticas, ideológicas y culturales, que se expandían alrededor de un nuevo mundo que se descubría, conquistaba y colonizaba.

No solo se interesaron por lo fenoménico sino también por las reacciones y conductas humanas de las generaciones de hombres y mujeres frente a sí mismos, a la sociedad y a la naturaleza. Las ciencias sociales y naturales trataron de investigar y descubrir la repitencia regular y constante de leyes, tendencias y transiciones históricas como un continuum histórico del devenir y porvenir de un nuevo orden social, que la sociedad podía explicarse con diversidad de categorías en torno a la democracia, el poder, autoridad, hegemonía y dominación creadas de los hechos empíricos. 
En esa la élite histórica de pensadores se autoformaron las primeras generaciones de sociólogos y sociólogas junto con el nacimiento o desarrollo de otras disciplinas: historia, economía política, psicología, educación, antropología como Ciencias Sociales. Dieron paso a la primera sociología empírica. Su desafío fue estudiar esa realidad y los escenarios de cambio social local y mundial, formulando hipótesis, teorías, métodos y leyes precientíficas provisionales que se formalizaron para explicar la constitución social y material de la nueva sociedad y civilización que emergía.

\section{El concepto de sociedad y el capitalismo liberal}

Las primeras concepciones sobre sociedad fueron fruto del cambio social de la vida cotidiana. Muchas ideas tradicionales se fueron reemplazando y hubo cambios en las formas de pensar la realidad, desde su concepción físico-natural hasta comprender el mundo social, regidos por leyes naturales o por leyes sociales.

- Sociedad-comunidad medieval. La herencia de la filosofía medieval dejó una concepción de sociedad muy simple, era un "todo orgánicamente unido, como comunidad, los lazos socioeconómicos eran inseparables de los morales, están personificados, obedecían a la tradición y a las normas religiosas" (Kon, 1989: 7).

- Concepción de los románticos conservadores tradicionalistas. Fueron los franceses Edmundo Burque (1729-1799), Luis de Bonald (1754-1840) y Joseph de Maistre (1753-1821) quienes criticaron el caos y la destrucción de la sociedad a la que dio origen la Revolución francesa, clamaron el retorno a la armonía y el orden del Medioevo. La sociedad la concebían como ente orgánico único, más importante que el individuo, su existencia es imposible al margen de ella, que lo precede y lo socializa para sus propios objetivos, está moralmente encima de ellos. Las leyes internas que la rigen radican en el pasado remoto. Lo que cuenta no son los individuos, sino según su posición; en las relaciones entre estructuras e instituciones cada uno cumple su función y papel determinado. "Todas las partes de este conjunto están relacionadas orgánicamente; si cambia una, cambia la otra" (Kon: 14). Y si se introducen cambios, debe ser con suma precaución (Ritzer-I 1994: 13).

\section{Las teorías naturales}

- Concepción mecánica. Esta teoría, considerada racionalista, redujo los hechos sociales a un número limitado de leyes generales inmanentes a la naturaleza; incluida la naturaleza humana. Su estudio de la sociedad se asoció con la "Física Social" (Kon, op. Cit.), concebida como un sistema astronómico de individuos relacionados por la atracción o repulsión social, así como se observaba a las estrellas y astros celestes en interacción mecánica. Los modelos de la Matemática (Geometría), Astronomía y Mecánica sirvieron para hacer 
las deducciones sobre lo social. Esta concepción varió cuando se desarrolló la Física de Isaac Newton, que fue menos mecanicista.

- Concepción organicista. El inglés Herbert Spencer (1820-1903) profundiza las ideas de Comte e introduce a las Ciencias Sociales las ideas teóricas creadas por la teoría de la evolución de Darwin. La sociedad es "un agregado social que tiene más semejanza con un agregado orgánico que con uno inorgánico, pues aumenta y evoluciona como un cuerpo organizado de células con existencia propia cada una de ellas. Si su existencia se corta bruscamente, los pequeños factores continúan viviendo todavía algún tiempo. Como cuerpo orgánico, nacen, viven y mueren en el mismo lugar, lo que los hace heterogéneos. Sus estructuras se complican cuando crecen y se van diferenciando desde las primitivas hordas errantes, casi homogéneas, hasta la tribu, que se distingue y diferencia por la ocupación de sus componentes.

Las clases sociales se establecieron cuando el gobierno se separó de la industria: los gobernantes se dividieron en políticos, militares y sacerdotes; los gobernados en artesanos y trabajadores; y cada uno se subdividió así, sucesivamente. Una sociedad civilizada envuelve ciertas disposiciones, ciertos caracteres de estructura que son permanentes y sobreviven a los individuos (Spencer, 1942: 64 ss.). De aquí se derivó posteriormente el "darwinismo social": en la sociedad sobrevive el más fuerte.

- La Sociedad-Estado. Fueron los enciclopedistas franceses quienes establecieron una diferencia entre Sociedad y Estado. La sociedad se concibió como modelo mecánico con división del trabajo e intercambio racional entre los individuos; una máquina estructural en la que se podía analizar y comprender las funciones reales de instituciones sociales o subsistemas; la economía y la cultura o el Estado y el Derecho, concebido como un derecho natural de origen contractual. La división de la estructura social-natural y los reglamentos jurídicos artificiales abrieron el camino hacia la comprensión de que la vida económica es independiente de la política (Kon: 8).

Con estas primeras concepciones de sociedad se fue acumulando el conocimiento necesario que posteriormente daría origen formal a la Sociología, con la que podría explicarse en forma científica las profundas transformaciones de la época.

En la transición histórica del siglo XVIII al XIX, surgieron nuevas concepciones de sociedad como reacción a que los cambios esperados por la Revolución francesa y el desarrollo industrial fueran favorables al desarrollo y al progreso. Estas concepciones fueron contradictorias, por la misma percepción y posición de clase de sus formuladores.

- Concepción liberal utilitarista. Otros pensadores de la época, los utilitaristas ingleses Jeremy Bentham (1748-1832) y James Mills (1773-1836), vieron 
a la sociedad como un cuerpo artificial, ficticio, compuesto de individuos que son sus unidades. Son superiores el individuo y la libertad de empresa (laissez-faire, laissez-passer); es la institución que se justifica por su utilidad. Su ley ética general fue asegurar el bien máximo del nuevo orden, pues sus relaciones son las que más benefician a la comunidad. Este liberalismo reconoció que solo la burguesía tiene la posibilidad de modificar, reformar y perfeccionar la ley (Kon: 15).

\section{Precursores de la sociología empírica}

La primera concepción fue durante el siglo XIX cuando surgieron los precursores y posteriormente lo fundadores. Ya había avances para comprender y controlar el universo mediante la razón y la investigación empírica en el período de la Ilustración; fue una ampliación de los esfuerzos teóricos realizados para reformular los mismos conceptos iniciales de sociedad y sociología. Se desarrollaron nuevas líneas teóricas de interpretación que dieron un paso más al nacimiento de la sociología empírica. La meta era comprender "la creación de un mundo más racional y mejor, rechazando las creencias en la autoridad tradicional - valores e instituciones de la Edad Media-, por irracional y opuestas a la naturaleza humana" (Ritzer-I, 1994: 11).

\subsection{Aportes de Adán Ferguson (1723-1816)}

Al inicio del siglo XIX, el escocés se preocupó por analizar empíricamente las graves consecuencias del desorden social ya existente en la sociedad. Desde una nueva percepción social explicó que la fragmentación de la comunidad y de la personalidad de los individuos se debía a los "efectos de la División del Trabajo que implicaba una mayor especialización requerida por los avances de la sociedad industrial" (Raison, 1970: 10). Que la "división social del trabajo" dio lugar a la división social de la sociedad y el de clase social, que se empezó a utilizar a diferencia de estamento, propio de la Edad Media.

Esta especialización la asoció con la Estratificación Social (fundamental en el objeto de estudio de la sociología clásica) en la que las clases sociales que se formaban eran producto de la desigual distribución de la propiedad, lo que daba lugar a las distintas subculturas y tipos de personalidad.

Con estas ideas elaboró dos teorías, una sobre la propiedad y otra sobre la alienación, (categoría clave para la sociología del materialismo histórico). Escribió "Un ensayo sobre la historia de la sociedad civil", el nuevo concepto fue considerado posteriormente por los especialistas en sociología como una obra de sociología sistemática evolutiva. Su nuevo concepto de sociedad se refería a una estructura integrada en la que la distribución de la propiedad es lo que confiere el poder y la riqueza. Aunque es fuente de progreso, de desarrollo social, de cambio evolutivo de la estructura social, también contiene el germen del conflicto social. 
El logro y mantenimiento de una civilización es una hazaña peligrosa, pues cada sociedad adquiere su estructura a un precio y esto es lo que le da su carácter (Raison: 19 ss.). Así construyó el concepto de sociología que utilizando la observación captaba la naturaleza de la sociedad y se derivaban proposiciones de nuevo tipo y originales. Sus generalizaciones sociológicas consistían en presentar una construcción racional en términos abstractos y ya no sólo empíricos (Raison, Op. Cit.).

El conjunto de nuevos conceptos reflejó "un período de notable desarrollo y cambio intelectual en el pensamiento filosófico y social" (Ritzer-I, Op. Cit). Se pretendía lo siguiente: analizar la situación en el trabajo, la movilidad profesional, el cambio de organización, los efectos sociales de los avances tecnológicos, la polémica sobre políticas mal estructuradas, la diferenciación, solidaridad y la evolución de la sociedad.

\subsection{Claude Henri, Conde Saint-Simon (1760-1825). Sociología y socialismo utópico}

Fue autodidacta y sistematizador de sus construcciones filosófico-científicas; se decidió por la Física, Matemática y Medicina para tratar de entender la Ley de la Gravitación Universal de Newton. Bajo la influencia de las ciencias positivas, predominantes en la Biología, Química, Física, que estudiaban los fenómenos de la naturaleza, intentó definir al nuevo régimen social en su funcionamiento como "fisiología social" (Raison, Op. Cit).

Como precursor y cofundador de la nueva disciplina científica, construyó su concepción de Sociología y aportó ideas básicas y nuevos contenidos a su objeto relacionados con la industria moderna y la reconstrucción total de la sociedad. El análisis de la crisis europea debía ser objeto de estudio de la Sociología. Observó que la sociedad pasaba por períodos: orgánicos eran cuando las instituciones políticas y sociales estaban en armonía con la civilización, a estos sucedían los críticos, que aunque transitorios eran conflictivos y corrosivos. Decía que el motor del cambio en la historia del mundo lo constituye el conflicto entre las clases sociales. Solo la industria podía poner fin a la revolución social.

El orden social y lograr un cambio social se mantienen a través de la planificación y la tecnocracia, que podría estructurar un capitalismo filantrópico. "Cuando exista una teoría correspondiente al presente estado de instrucción, se restaurará el orden, se establecerá una institución común a todos los pueblos de Europa y un sacerdocio convenientemente educado en la ciencia, traerá la paz frenando la ambición de pueblos y reyes" (Ibíd.).

Intentó describir a las emergentes clases sociales. La nueva clase que sustituiría a la monarquía constitucional son los propietarios, banqueros e industriales. Los sacerdotes serían una especie de elite intelectual de científicos, artistas y hombres de ideas. 
La otra clase de la sociedad eran los trabajadores, a la que consideró como clase productiva. Estos pueden intercambiar con libertad los productos de su trabajo, ya que forman la comunidad real. Las preocupaciones sobre esta clase lo llevaron a pensar ideas socialistas utópicas; consideró que se debía renovar las elites para evitar que la industria destruyera a la sociedad; evitar que esta destruyera a la industria y que ambas destruyeran al ser humano. Con esta visión previó la "necesidad de reformas socialistas, especialmente la planificación centralizada del sistema económico" (Ritzer: 15). Por esta posición fue procesado por subversión.

Su concepción de gobierno como poder político y fundamento de la autoridad permitió un tipo de integración y una estructura social nuevos, que con su producción industrial reemplazará el viejo sistema jerarquizado y subordinado (Raison, Op. Cit.).

La sociología de Saint-Simon que aportó nuevas concepciones sobre las leyes de la vida social y estableció bases para las ciencias positivas ejerció una fuerte influencia en el liberalismo francés e inglés, en el nacionalismo italiano y en el socialismo de Marx y Engels.

\section{Fundadores de la Sociología. Postulados teóricos y metodológicos}

\subsection{Augusto Comte (1798-1857). La Sociología Positivista}

La fuerte influencia de las ciencias positivas de la naturaleza (Física, Química, Biología...) se aplicó en los fenómenos sociales y humanos. Augusto Comte y otros pensadores se anticiparon a observar y analizar las emergentes estructuras sociales de la realidad empírica. En 1839 este filósofo positivista francés rechazó y sustituyó la concepción de fisiología social y la de física social (Timasheff, 1983: 16). Propuso las "primeras concepciones de una nueva ciencia que denominó 'sociología' para estudiar y conocer la llamada sociedad" (Elías, 2006: cf, P. 41). Al inicio hubo dudas sobre este invento. En Alemania, George Simmel (1858-1918) se dio a la tarea de explicar que "la pretensión científica de la sociología como nueva ciencia homogénea generaba un caos de opiniones sobre sus contenidos, metas, contradicciones, falta de claridad y de delimitaciones seguras que contuvieran el hecho o concepto de 'sociedad' como punto común de conexión...; sí daba cohesión y brindaba una ubicación provisional de solución a los diversos problemas" (Simmel, 2012: cf, pp. 23, 24).

Se interesó por investigar, explicar y categorizar científicamente modernos procesos integradores que se reestructuraban y consolidaban como nuevas relaciones entre clases sociales, familias, comunidades e instituciones: mercado, Estado, Ejército, Iglesia, jurisprudencia, arte, literatura y otras. Así, la Sociología, como ciencia teórica, se inscribió a las ciencias positivas para el análisis de la sociedad. El analista Kon (cf. p. 20 ss.) comentaba que "esto marcó el triunfo de una nueva etapa de la revolución positiva del desarrollo del intelecto y la so- 
ciedad humana sobre la escolástica de las épocas precedentes, pues se dedicará a las investigaciones positivas sobre las leyes fundamentales, inherentes a los fenómenos sociales".

Su positivismo es como la nueva religión de la humanidad, los sacerdotes son los intelectuales, científicos y artistas; su Dios es ahora la sociedad, a la que se debe venerar como un ser supremo, pues es a quien le debe todo (Kon: Op. Cit). Su Sociología construyó parte de su objeto de estudio enriquecido por las innovaciones que ya la Ilustración y las Revoluciones francesa e Industrial inglesa habían anticipado. Se fue constituyendo en un sistema especializado del saber, con un proceso de formación, transformación y desarrollo de los conceptos o categorías de distintas corrientes de pensamientos que ya circulaban en esa época, como la positivista y la materialista.

\subsection{Principales aportes teóricos: un nuevo concepto sociológico de sociedad}

- Tres estadios recorridos por la humanidad/sociedad. Un aporte fundamental de la filosofía positiva y la sociología de Comte es que "desarrolló una teoría sociológica del pensamiento y la ciencia que vinculaba en tres grupos: físico, biológico y el sociológico independiente de los dos primeros. Formuló una 'ley del desarrollo social': cada una de nuestras concepciones principales, cada rama de nuestros conocimientos atraviesa sucesivamente tres estadios teóricos diferentes: a) Teológico o ficticio (religión); b) Metafísico o abstracto (filosófico) y c) Positivo o Científico (nuevo orden y progreso basado en la industria). En las investigaciones son tres métodos: teológico, metafísico o positivo" (Elías, Op. Cit, p. 44).

Como ciencia positiva, su sociología destaca la separación de la Metafísica y la Teología; concibió que los hechos sociales no están separados unos de otros, sino que tienen nexos mutuos y están enmarcados con el conocimiento que los seres humanos tienen de sí mismos. Su principal postulado metodológico fue que lo positivo significó lo orgánico, determinado y preciso; lo real, útil, fidedigno y exacto, en contraposición con lo quimérico, inútil, dudoso, confuso y negativo. Su primer salto de calidad fue respecto a las concepciones tradicionales de sociedad. Su nueva misión: descubrir leyes que son expresión de relaciones permanentes y repetidas entre fenómenos, a fin de lograr conocimientos exactos y prever el futuro. Comparó la estructura y cualidad de los organismos y fenómenos de la vida correlacionados con la época, la civilización y la humanidad. Así completó sus categorías para darle un carácter universal. La principal preocupación de Comte fue el poder introducir a las ciencias humanas los métodos de las ciencias naturales (ver: www.taringa.net)

Estudió el perfeccionamiento intelectual y la psiquis humana, bajo la influencia de la vida social. El ser humano como abstracción y la sociedad como realidad, están supeditados a las leyes naturales y a los fenómenos sociales que cambian, 
se modifican y se desarrollan en el tiempo, cuya esencia es la historicidad. En este proceso social se dio el progreso del pensamiento científico, que fue conformando el desarrollo de la historia y el de la humanidad como realidad suprema.

- Estática social. Referida a la Teoría del Orden, organización y armonía sociales, como condición de existencia de las leyes del funcionamiento del sistema social.

- Dinámica social. Son las leyes del desarrollo y modificación de los sistemas sociales. La Sociología se fue institucionalizando en la medida en que analizaba la sociedad como un "todo orgánico, cuya estructura relacionada entre sí asegure la armonía y el orden. Esto sólo es posible lograrlo a través de la familia, el Estado-gobierno y la religión, que son las instituciones cuyas funciones pueden lograr la integración social” (Kon, Op. Cit.).

- Sociedad y división del trabajo. La concepción sobre División del Trabajo difiere de la que ya habían esbozado otros pensadores; la excesiva especialización descompone la sociedad, destruye la unidad, engendra competencia, explotación y despierta bajos instintos. Por ello rechaza el principio de laissez-faire, laissez-passer, por ser absurdo y poner de relieve el egoísmo de la naturaleza humana, es así como relega a segundo plano las relaciones económicas. Lo que supone el relieve es la armonía social, la cooperación y el consenso (Kon, Op. Cit.).

- Estado y el gobierno. Las otras instituciones de mayor importancia para la Sociología es el Estado y el gobierno, tomados como objetos de estudio de la naciente Sociología. Al Estado hay que obedecerlo como un deber sagrado, pues es el órgano de solidaridad social, el guardián del orden público que cumple funciones económicas, políticas y morales; estas dos últimas son las más importantes, mientras el gobierno es el poder político y exponente del espíritu común, cuya misión social es prevenir la discrepancia radical en las ideas, la descomposición y alteración de su unidad orgánica.

- Orden y progreso. En la sociología de Comte no se puede concebir el orden sin el progreso, este es el "desarrollo social ascendente de carácter primario como lo espiritual e intelectual y secundario referido al clima, a la raza, longevidad de los seres humanos y al incremento de la población, que puede aminorarlo o acrecentarlo en la historia de los pueblos. El progreso puede ser material - mejoramiento de condiciones externas de vida-, físico — perfeccionamiento de la naturaleza humana —, intelectual — paso del mundo religioso y metafísico al positivo- y moral — sentimientos morales y espíritu colectivista-.

- Familia y género. Su concepción de familia fue contradictoria en relación con el género. La consideró como la unión moral y emocional basada en el cariño y la simpatía mutua. Su misión es educar a las nuevas generaciones 
en el espíritu del altruismo y ayudarle a vencer el egoísmo innato. Debe socializar para poder ser útil y aprender a vivir con los demás, con base en relaciones equilibradas entre las generaciones de viejos y jóvenes y con sentimientos sociales, emocionales, de cohesión y de solidaridad. Ser fuente de educación moral y ser la base de la organización política, pues debe preparar la sociedad futura y prolongar su vida. Su contradicción respecto al género fue muy cruel porque se contraponía a la igualdad entre el hombre y la mujer, considerando que ella está por debajo del hombre en el plano intelectual y en la fuerza de voluntad. Mientras él, como padre y marido, deberá afianzar la autoridad y el poder.

El impacto de la Sociología sobre las demás ciencias se hizo sentir en la Historiografía, Lógica, Psicología, Literatura, etc., y en otros pensadores de la época como Emilio Durkheim. La Sociología fue incorporada en las principales aulas universitarias europeas (Francia, Alemania, Gran Bretaña...) y posteriormente fuera del continente. En 1848 formó la Sociedad Positivista con sus alumnos para educar e instruir al pueblo en la concepción positiva del mundo.

Principales obras de Augusto Comte:

- Curso de Filosofía Positiva (1830-1842), referido a la clasificación de las ciencias, la filosofía positiva y la sociología.

- Sistema de política positiva o tratado de Sociología (1851-1854), que sentó las bases de la política y la religión futuras.

\subsection{La Sociología de Emilio Durkheim (1858-1917)}

- Sociología, ciencia de la sociedad. Llamó a la Sociología ciencia de lo moral, dándole el carácter de disciplina científica (Torres-Rivas: 18). Fue influenciado por la moral del neokantismo alemán, que era la moral intelectual, abstracta e independiente de la voluntad del hombre. Consideró que las reglas morales debían estudiarse científicamente y no en forma metafísica e irracional, como las ideas religiosas primitivas.

Propuso que la sociedad es como una propiedad colectiva referida a la economía, al arte, a la cultura y que todos los individuos deben respetar y acatar las normas, que son como dogmas religiosos. En su primera obra, Las formas elementales de la vida religiosa, identificaba a la sociedad con Dios y buscaba la manera de mejorar su funcionamiento. Se interesó además por el utilitarismo de Spencer, que trataba sobre lo bueno que produce placer.

- Solidaridad mecánica, solidaridad orgánica. En 1893 escribió La división del trabajo social, para tratar de explicar que esta división era muy elemental en las sociedades primitivas y por ello eran más estables, pues los individuos eran iguales y la religión era el cemento unificador, que generaba una solida- 
ridad mecánica porque el interés de uno depende del interés del otro, y eso crea cohesión (Torres-Rivas, Op. Cit.).

Esto no ocurría en la sociedad industrial porque por la creciente especialización se dio un individualismo creciente por el predominio del ideal liberal, los vínculos son más difusos y el hombre vale por lo que hace y realiza. De ahí que el progreso y el desarrollo son más complejos, porque la sociedad se va diferenciando en su orden, cohesión y unanimidad, es decir, se va polisegmentando, por ello surgen las normas, leyes, códigos que rigen la sociedad y reproducen las normas morales. En la complejidad de la sociedad industrial la tendencia es aplicar sanciones y no castigos para reformar. Ese mecanismo de aplicación de sanciones restitutivas, que parte de las creencias y costumbres con consecuencias colectivas, le llamó solidaridad orgánica (Torres R, Op. Cit.).

- Normas y valores morales. Durkheim, al igual que sus antecesores Saint-Simon y Comte, temía y odiaba el desorden social reinante en la sociedad, que se manifestaba en conflictos laborales, discordia entre la Iglesia, el Estado y el nacimiento del antisemitismo político. Además del estudio de la moral, analizó la aplicación de las normas desde el Derecho y consideró que detrás de la norma legal hay una moral, donde se encuentran formas de solidaridad como interdependencia colectiva. Con ella se establecen normas y valores y en la medida que se cumplen hay orden e integración; cuando no se cumplen se cae en un estado de anomia, que es una conducta desviada. La anomia, como categoría sociológica, estudia y analiza la disfunción de la sociedad; puede ser individual y colectiva, en la primera están los delincuentes, en la segunda las revoluciones sociales. Su propuesta para ello fue el control social, el orden, la integración, la moral y la religión, que podía solucionarse mediante la introducción de reformas sociales (Ritzer: 18 y Álvarez-Uría: pp. 116 y ss).

- “Hechos sociales", investigación y métodos. La sociología de Durkheim se caracterizó porque, en la medida que la sociedad se fue institucionalizando, seguía siendo estudiada por intelectuales que dieron un paso más; surgieron nuevas praxis científicas y concepciones sociológicas en la construcción de su objeto de estudio con teorías, métodos y técnicas de investigación. Sus niveles de análisis científico fueron articuladores de procesos micro y macrosociológicos, incorporó como postulado la metodología de investigación a partir del estudio empírico de los "hechos sociales" sobre los problemas de lo humano. Los hechos sociales son considerados como "cosas", pero no objetos codificados o "datos" empíricos, exclusivamente, sino procesos sociales caracterizados por una exterioridad, así, por ejemplo, cuando un individuo nace ya encuentra la sociedad dada y se convierte en un elemento de la totalidad-sociedad. Con este orden moral y de coacción el hecho social se caracteriza por la coerción, pues deben acatarse sus normas, leyes y códigos y ser aceptados como tal, por ello el individuo debe ser socializado para formar la conducta y actuar bajo las normas que la sociedad impone. 
Dos trabajos sociológicos muy importantes construidos a partir de la aplicación del nuevo método de investigación fueron "Las reglas del método sociológico" y "El suicidio". El primero se refiere al estudio específico de los hechos sociales que deben ser descubiertos a través del método empírico; a preguntarse por las causas que producen fenómenos y las funciones que deben dar viabilidad a la sociedad. En el segundo se aplica la estadística con la que se indica el número de gente que se suicida en determinados períodos y épocas de crisis en la sociedad. El suicidio puede ser: a) Egoísta, ocurre cuando una persona hace prevalecer su "yo individual" por sobre el "yo social". b) Altruista, es la muerte como parte de un código de honor; ejemplo: el harakiri que aplicaban los japoneses en la guerra por honor a la patria o por lealtad al jefe superior. c) Anómico, cuando los desempleados entran en un estado de depresión y angustia, ante la pobreza y la desintegración que produce una crisis económica o política.

Otros aportes de la Sociología como ciencia son el análisis sobre la religión y la cultura, que son fenómenos generadores de sistemas de símbolos, ya sea religiosos o políticos, que permiten cohesionar a la población cuando existe crisis en la sociedad y su estado es anímico. Lo que procede es encaminarse a la concertación y el consenso para lograr acuerdos que atiendan los intereses de la sociedad para construir de nuevo la solidaridad y cohesión. Los himnos, los ritos, las marchas, etc., son símbolos místico-religiosos y políticos que ayudan a lograr la identidad de las personas que buscan la cohesión entre sí.

Emilio Durkheim dio el sello académico a la Sociología. Con toda esta riqueza, la afincó como una ciencia social de indiscutible carácter científico, tanto en lo académico como extraacadémico. La incorporó definitivamente en los cursos de las universidades en Francia, que luego e extendió a otros países europeos. Su sociología intentó explicar las desigualdades de la economía capitalista industrial, investigó los fenómenos más relevantes de la sociedad humana del fin del siglo XIX, que ya transitaba para el XX.

\subsection{La Sociología comprensiva de Max Weber (1864-1920)}

Coetánea con las primeras concepciones sociológicas de la época, también se conoció el pensamiento del alemán Max Weber. Trató de explicar el surgimiento del orden social capitalista como civilización occidental europea, comparándola con la civilización oriental de la vida cultural y religiosa de oriente (China, India). Es decir, comparó la emergente sociedad moderna. Hizo esfuerzos intelectuales por investigar procesos y acontecimientos de carácter macro y micro de finales del siglo XIX y primeras décadas del XX (revolución bolchevique rusa y primera guerra mundial).

Conoció el pensamiento sociológico de A. Comte, Ferguson, Saint-Simon y Durkheim, pero sus conceptos fueron muy diferentes: 


\section{- Teoría de la acción social, Tipos Ideales y Carisma}

Aportó un nuevo concepto que llamó Sociología comprensiva que complementó con la Teoría de la acción social. La describió como la ciencia que pretende entender la "acción social", interpretándola. Con ella se estudia a los sujetos humanos y su conducta referida a su sentido y significados concretos. Aportó su metodología del llamado tipos-ideales con significado hipotético-ideal (Ritzer, Op. Cit), es decir, son mecanismos conceptuales para estudiar la realidad y elaborar construcciones intelectuales para su análisis como conexiones de sentido. Con estas aproximaciones se organiza la investigación provisional y luego en el proceso se va modificando en la medida que se va enriqueciendo (Ibid). Se aplica en el estudio de la sociedad y la cultura y consiste en "enfocar cosas particulares, conocer sus rasgos susceptibles de observación y medición exactos" (Raison: 175).

- Cuatro tipos ideales de orientación racional. a) Con arreglo a fines (es el cálculo para actuar). b) Con arreglo a valores (es la consecución de un ideal). c) Acciones afectivas (alcanzar el ideal con lo emotivo, tiene fines más espirituales) y d) Acción tradicional (es la de sentido común).

Así como construyó su método elaboró nuevos conceptos para sus propuestas teóricas. En sus principales obras, Economía y Sociedad, estudió grandes fenómenos explicados como teorías que establecen una relación entre el crecimiento económico y las formas religiosas de la vida, que intermediaban los tipos de autoridad y gobierno. Con otras teorías sociológicas daba explicaciones sobre la burocracia, las clases sociales, corporaciones, status de grupos, Partido, tipos de ley y sistemas como nuevos aportes para comprender los sucesos de la sociedad alemana.

En otro libro, Ética protestante y el espíritu del capitalismo, amplió la explicación económica de cómo el protestantismo religioso rompió con la tradición religiosa. Esta facilitó el desarrollo económico, pues había una ética, tanto para el trabajador, quien con su ethos - espíritu de trabajo- y sus creencias religiosas buscaba más la tranquilidad que la riqueza. El empresario debía ser disciplinado y conformarse con el duro trabajo, ya que esta es una profesión y una vocación que apareció con la Reforma y no con el catolicismo. El empresario católico derrocha sus ganancias; el empresario ascético las ahorra para aumentar la predestinación, la felicidad eterna y de por vida, pues ha sido escogido por Dios (Torres Rivas. Op. Cit.).

- Carisma y teoría de la burocracia. Desarrolló categorías que esbozaron una sociología política organizada alrededor de las acciones que, como las normas y reglas, construyen un orden legítimo basado en la autoridad. El carisma es una virtud para convencer a los ciudadanos respecto al poder inmanente que reviste el ser papa del Vaticano, rey, jefe, presidente de determinada población o sociedad. Esa autoridad debe legitimarse y puede expresarse ya como un don de carácter carismático o burocrático-racional, que lleva a la 
obediencia. De aquí surge su teoría de la burocracia, a la que considera que es el sector capaz de manejar la administración con eficacia, imparcialidad, secretividad y de manera impersonal, para cumplir las leyes de la empresa o del Estado.

Weber contribuyó a definir sus propios conceptos ampliando y enriqueciendo los aportes de Ferguson, Saint-Simon, Comte y Durkheim. A través de sus obras escritas dio un salto de calidad al utilizar creativamente categorías de racionalidad, clase, poder, dominación, autoridad y otras constitutivas de teorías innovadoras y explicativas de fenómenos históricos y contemporáneos. Su contribución al objeto de estudio se toma como sociología clásica.

\subsection{Carlos Marx (1818-1883) y Federico Engels (1820-1895). Aportes a la Sociología.}

En esa misma época surgieron los planteamientos teóricos y metodológicos de Carlos Marx y Federico Engels no solo para la sociología, sino para la economía política, la educación, la cultura y otros enfoques. Sus puntos de partida fueron la misma realidad europea que vivieron y analizaron Comte, Durkheim y Weber. Su influencia trasciende durante el siglo XIX, evoluciona con las realidades del XX y del presente, al igual que de los otros pensadores del momento histórico.

Sus investigaciones enfatizaron el análisis de las relaciones humanas bajo el impacto transformador del desarrollo económico, social, político-ideológico de la industrialización capitalista. Como emergente orden social, configuraron la lucha antagónica entre clases sociales (burguesía-proletariado y motor de la historia en la sociedad), un nuevo Estado y el mercado. Tuvieron presente la Filosofía, la Historia y otras disciplinas de las Ciencias Sociales en proceso de consolidación científica. Tomaron la dialéctica hegeliana idealista y la transformaron radicalmente en dialéctica materialista (uso metodológico de la categoría totalidad dialéctica) para estudiar los profundos cambios sociohistóricos.

Los escritos de Marx y Engels describieron los escenarios históricos de la nueva civilización capitalista. En su obra monumental El Capital explica los procesos de acumulación originaria transformada posteriormente en capital comercial, agrario e industrial. Brevemente se resume así:

Marx y Engels criticaron a la sociedad capitalista, produce la mercancía preñada de plusvalía extraída a la clase trabajadora fabril asalariada y reproducida como acumulación de capital industrial por la naciente burguesía a través de la invasiva expansión del mercado a escala planetaria. Señalaron los horrores y la explotación de los trabajadores (Ritzer: 28). 
Algunas categorías principales de análisis son las siguientes :

- Modo de producción: "Proceso de producción que condiciona la vida material, social, política e intelectual en general. A cierto grado de desarrollo de las fuerzas productivas materiales de la sociedad entran en contradicción con las relaciones de producción existentes, se convierten en traba y abren una época de revolución social que revoluciona la base económica y toda la inmensa superestructura erigida sobre ella" (Marx citado por Torres-R, Op. Cit).

- Relaciones sociales de producción: articulan las fuerzas productivas, que son las que permiten a los seres humanos transformar la naturaleza a través del trabajo y da lugar a la división social del trabajo, y, mediante la tecnología creada, es capaz de transformarse él mismo e innovar también a la sociedad. Los autores señalados explican el cambio social de la sociedad en todos sus órdenes, lo que altera las formas de vida, de pensar y sentir, la cooperación, la cultura, etc. Puede dar paso a una sociedad socialista como primera fase y pasar posteriormente al comunismo (Ibid).

- Alienación: lo que los seres humanos crean se vuelve contra ellos. Se convierte en fuerza enemiga, externa, que subyuga; por ejemplo: el dinero, que esclaviza (Ibídem.).

No es posible ampliar otras categorías claves y teorías para comprender la compleja realidad de la sociedad humana.

Algunas obras principales: El Capital, El Manifiesto del Partido comunista, El origen de la familia, la propiedad privada y el Estado, La sagrada familia, Miseria de la filosofía y otras.

El pensamiento marxista clásico llevó a comprender los cambios revolucionarios que transformaron estructuras caducas en la sociedad agraria o industrial capitalista. Se debilitó cuando se dogmatizó y sacralizó como la única fuente teórica explicativa de la realidad concreta. Muchos repetidores del marxismo hicieron perder el espíritu revolucionario y la verdadera esencia de la auténtica dialéctica: la primera inspiración es la demolición de todos los conceptos adquiridos que no permiten captar las tonalidades reales en movimiento, ni dar cuenta de la penetración profunda en las riquezas inagotables de la realidad (Gurvitch, 1971: 8).

La Sociología retoma los valiosos aportes de muchas teorías que son componentes parciales de su objeto de estudio en referencias al desarrollo histórico de la sociedad en sus diferentes procesos económicos, políticos, sociales, culturales y otros fenómenos surgidos el siglo XX que se proyectan al XXI. 


\section{Segunda parte}

\section{Expansión de la sociología en el siglo XX}

\section{De Europa a Estados Unidos}

Las élites de pensadores clásicos de la sociología dejaron una herencia científica sobre acontecimientos de gran impacto en la sociedad humana, continuó en el siglo XX y sigue en los primeros tres lustros del XXI.

Del acervo histórico de conocimientos (filosóficos, económicos, políticos, sociológicos, antropológicos y otros, incluyendo el de las Ciencias Naturales) han surgido dos grandes matrices de corrientes del quehacer del pensamiento teórico, metodológico y práctico para investigar y explicar una diversidad de fenómenos humanos, sociales y de la naturaleza. En el tránsito de la sociedad moderna del siglo XX a la posmodernidad del presente, tienen presencia las siguientes dos corrientes y diversas escuelas sociológicas:

\section{a) EI estructural-funcionalismo}

Del positivismo se organizaron tendencias intentando repetir, profundizar o criticar planteamientos de Comte, Durkheim y Weber o de Marx alrededor de la sociedad industrial capitalista.

La Sociología positivista evolucionó en la marcha del capitalismo industrial (Inglaterra y Estados Unidos), afincándose en la fase imperialista que expresa el poder geopolítico, autoritarismo, dominio y la hegemonía económica de la burguesía liberal sobre el mercado mundial. Los grandes acontecimientos históricos de la primera mitad del siglo dieron lugar a diferentes coyunturas de impacto que transformaron las nuevas realidades de la sociedad con fuertes repercusiones represivas a pensadores e intelectuales de las Ciencias Sociales que las analizaban: primera gran crisis capitalista en 1929 (caída de la Bolsa de Valores, Nueva York-EE. UU.); dos guerras mundiales que estremecieron a los países capitalistas europeos y euroasiáticos con los efectos de la "Guerra fría" y la doctrina de la seguridad nacional.

La herencia sociológica se reorganizó en distintas escuelas a partir de las décadas de los años 30 a los 70 . Nuevos sociólogos estadounidenses y europeos interpretaron y teorizaron fenómenos con perspectivas desde lo macro y micro enfoques de las relaciones socioeconómicas y político-militares, creando las teorías de esta corriente, tomando los fundamentos teórico-metodológicos de los clásicos e iniciaron la etapa posclásica con las escuelas de Chicago y Harvard, iniciando y consolidando el lenguaje categorial y teórico básico y aplicarlo en común para la sociología general y avanzar en las investigaciones de la realidad de ese período histórico. 
En EE.UU. sobresalió Talcott Parsons, heredero de Weber. En 1937 consideró que la sociología está atravesando por una nueva etapa como disciplina científica. Desarrolla un nuevo concepto de sociedad desde la corriente estructuralista: "Es un sistema o estructura social con institucionalización de patrones culturales (personalidad-socialización) autosubsistente que cumple tres (3) requisitos: a) organización de relaciones territoriales y parentesco, b) sistema que determina funciones y asigna facilidades y recompensas y c) está formada por estructuras integrativas controladoras de asignaciones, regulan conflictos y procesos competitivos" (Parsons, a y b)

Publica su obra La Estructura de la Acción Social, integrando también teorías de Durkheim y Weber para entender una nueva forma en que la sociedad funciona como sistema, subsistemas y modelos; sus teorías van desde lo "Voluntarista de la acción", los modelos "Trisistémico", "Estructural funcionalista" hasta el "Esquema cibernético". Los subsistemas son los siguientes: adaptativo, función de logros y metas, función de integración y el cultural, con la función de latencia. La principal crítica a su pensamiento es la de no considerar el cambio social como componente básico de la sociedad capitalista (ver: www.taringa.net).

Robert K. Merton destacó en la corriente funcionalista la siguiente: criticó a Parsons por la construcción de una sola teoría general y amplia de la sociedad; en cambio, postuló las teorías de alcance intermedio con las nociones de funciones sociales latentes y funciones sociales manifiestas, para el estudio focalizado de problemáticas sociales determinadas. Alfred Schütz inició los estudios sobre la fenomenología; y Harold Garfinkel, creador de la etnometodología, que pretenden el estudio social de las conductas de los individuos en la vida cotidiana, criticando los modelos de las teorías sociológicas que toma a la sociedad como un cuerpo propio de estudio (Ibid). George Herbert Mead propuso el estudio de la sociedad humana universal, la interacción simbólica con las propuestas del self y la interacción, y C. Wrigt Mills (1916-1962) propuso el estudio de la teoría del conflicto y la élite del poder, en oposición a T. Parsons, desarrollando su "Imaginación Sociológica" (Vargas-Mendoza). Otros sociólogos estadounidenses son Robert Park y Ernest W. Burgess (estudios de sociología urbana), George Homans, Herbert Blummer. Su influencia aún permanece en la sociedad norteamericana.

En Europa surge posteriormente la escuela de Francfort, que crea una corriente sociológica a partir de la teoría marxista con la "Teoría Crítica de la Sociedad", los principales exponentes son T. Adorno, Horkheimer y Marcuse. En esta escuela de Frankfurt (Alemania) también ha destacado J. Habermas, que ha desarrollado una integración de teorías entre neofuncionalismo, neomarxismo y la ética comunicacional. Considera que hay un progreso real en las sociedades modernas en comparación con las premodernas; difiere con posmodernistas como Lyotar, Foucault y Derrida (Vargas-Mendoza, Op. Cit). 
De la escuela francesa vale destacar al sociólogo francés Pierre Bourdieu, muy crítico, que al referirse a la relación de la Sociología como ciencia y su objeto de estudio sobre qué debe estudiar anota lo siguiente: “...aunque la sociología hace mucho tiempo salió de la prehistoria... sí es una ciencia difícil pues cuando levanta velo y saca a la luz cosas ocultas, escondidas, censuradas y a veces reprimidas se torna agresiva y perturbadora; por provocar la crítica a ciertos sectores produce miedo y desencanto..." (Bourdieu: 2).

La influencia sociológica europea en latinoamérica tomó forma en el contexto de la Guerra Fría en la possegunda guerra mundial a mediados de siglo. Las múltiples teorías esbozadas como paradigmas del funcionalismo estructural y el marxismo clásicos y posclásicos o contemporáneos continúan explicando parcialmente fenómenos sociales estructurales, pero ampliando o criticando parte de su riqueza teórica-metodológica.

Gino Germani (italiano) creó en la Universidad de Buenos Aires la carrera de Sociología. En 1955 inicia la teoría de modernización como corriente sociológica. Su principal obra, Política y Sociedad en una época de transición (1965). propone su conceptualización sobre los efectos de fusión y demostración, dentro de los fenómenos de asincronía, el desarrollo de las nociones de países desarrollados, en vías de desarrollo y subdesarrollados. A finales del siglo XX las coyunturas de la sociedad impulsan la innovación de la Sociología hasta el presente. En Centroamérica, las universidades mantienen en sus currículo los estudios de los pensadores clásicos, contrastando con los posclásicos del presente, incorporando o creando nuevas teorías o paradigmas apropiados a las realidades de la vida cotidiana.

\section{b) El materialismo histórico-dialéctico}

Esta corriente teórica surgió del pensamiento económico, político y sociológico de Marx y Engel como antítesis al capitalismo en europa. Ideólogos de la clase proletaria o trabajadora asalariada retomaron fundamentos teóricos de esta propuesta y formularon una variedad de teorías revolucionarias y métodos de investigación basados en la dialéctica de las contradicciones y la lucha de clases (sistema categorial, hipótesis y paradigmas transformados en prácticas cotidianas). Fue una crítica a la filosofía liberal de la economía política y la acumulación de capital/plusvalía por la burguesía.

Entre las revoluciones sociopolíticas que estimuló fue la revolución bolchevique (1917) al implantar el socialismo de Estado (¿ideas parciales de la propuesta teórica de Saint Simon, ya citado?) como Unión de Repúblicas Socialistas Soviéticas (URSS) al iniciar el siglo XX, de amplia repercusión mundial, destacaron V. I. Lenin, J. Stalin, Nicolai Bujarin, León Trotsky y otros. Rosa Luxemburgo, en la fracasada revolución alemana. La Revolución cultural de Mao Tse Tung (1948) en China/Asia. Al finalizar el siglo XX, la herencia "sociológica" clásica de la práctica del marxismo se debilitó con el derrumbe 
del socialismo real de la URSS y la demolición del muro de Berlín en Alemania. Esta corriente, sometida a críticas epistemológicas, teóricas, metodológicas y prácticas, inspira las luchas populares de los nuevos movimientos sociales antiglobalización y antisistema.

El capitalismo, y el socialismo, y sus contradicciones en la sociedad mundial y local, han generado acelerados cambios transformadores, dando apertura a los nuevos tiempos que continúan desafiando al pensamiento sociológico y de las Ciencias Sociales. Las dos corrientes tradicionales tienden a renovarse e innovarse, creando una variedad de teorías sociológicas conocidas como neofuncionalistas, neo o post estructuralistas o postmarxistas frente a fenómenos inéditos en una realidad cada vez más compleja.

Vale adelantar que en el presente una nueva la élite estadounidense de destacados pensadores con una visión más crítica desarrolla investigaciones teórico-metodológicas mucho más cualitativas e integradoras de micro y macro fenómenos mundiales en los procesos de globalización, que hegemonizan la sociedad mundial; entre otros Noam Chomsky, Inmanuel Wallerstein.

\subsection{La sociología en las revoluciones de América Latina y Centroamérica}

Por el espacio limitado del artículo solo es posible hacer algunas referencias generales. El desarrollo de la Sociología se impulsó desde la universidad casi a mediados del siglo XX, en su evolución se ha diversificado en una proliferación de especialidades (referidas a la familia, educación, religión, lo urbano-rural, ambiental, de la organización política de los partidos y movimientos políticos, de género y otras). Lo importante es indicar que ha surgido una nueva élite más crítica en cada sociedad, que es un laboratorio sociológico para la investigación de nuevos fenómenos del capitalismo liberal y neoliberal.

En América Latina (Suramérica-Centroamérica), de la década de los años 30 en adelante hubo alguna influencia teórica marxista. José Carlos Mariátegui, en Perú, desarrolló un pensamiento marxista apegado a la realidad que vivía la población indígena. En el Caribe la Revolución cubana, inspirada por el patriota José Martí, llevó a Fidel Castro (1959) y Ernesto Ché Guevara (argentino) a implantar el modelo socialista en la sociedad cubana. En las siguientes décadas influenció otros procesos revolucionarios que motivaron el surgimiento de las guerrillas a lo largo de varios países latino y centroamericanos ante la represión impuesta por regímenes militares dictatoriales proimperialistas.

Desde mediados y finales del siglo XX, el movimiento acelerado de la realidad obligó a hacer los máximos esfuerzos desde la Sociología para reestudiar e investigar fenómenos históricos de Latinoamérica y así construir nuevas categorías, teorías y métodos apropiados a procesos coyunturales y cambios estructurales del momento histórico en cada sociedad. Se formuló la Teoría de la dependencia, de Theotonio Dos Santos y Aníbal Quijano (Brasil y Perú), 
en la década 1970, que hizo eco a escala continental. Así se ha constituido una élite de intelectuales, entre otros: Pablo Gonzáles Casanova (mexicano), Edelberto Torres Rivas, Daniel Camacho, Rafael Menjívar (centroamericanos); Fernando H. Cardoso, Vania Bambirra, Octavio Ianni (brasileños) y Atilio Borón (argentino).

A finales de siglo se reflejan elementos teóricos del neomarxismo propositivos de nuevos modelos revolucionarios de sociedades en proceso de descolonización del imperialismo capitalista, entre estos: Bolivia con Evo Morales; Venezuela, con Hugo Chávez-Nicolás Maduro, y Ecuador, con Rafael Correa, como "socialismos del siglo XXI".

En Centroamérica, la revolución de 1979 en la Nicaragua del Frente Sandinista de Liberación Nacional (FSLN) tuvo como antecedente el pensamiento antimperialista de Augusto César Sandino. En la actualidad el FSLN ha organizado un modelo de sociedad, pero en alianza con sectores oligarcas. En El Salvador, esta corriente alcanzó a la Sociología y a las Ciencias Sociales en las universidades y en el seno de la sociedad civil (sindicatos, movimientos populares...). Los incipientes ideales marxistas de Farabundo Martí de los años 30 los heredaron Cayetano Carpio y Jorge Schafik Handal y Salvador Sánchez Cerén, con la revolución del Frente Farabundo Martí para la Liberación Nacional (FMLN) [1980-1992]. A finales de la primera década del siglo XXI el movimiento popular y el FMLN con una ideología cercana al marxismo y bajo el peso de las políticas neoliberales, intenta construir un nuevo modelo de desarrollo económico-social. Por la vía electoral se instauraron los primeros gobiernos de izquierda: "del cambio y el buen vivir", desde 2009 al presente 2016, con apoyo de Estados Unidos (Fomilenios I y II). Esta nueva realidad centroamericana desafía y exige nuevas interpretaciones a la Sociología académica y extra-académica.

Las universidades, élites, círculos, organismos e instituciones dedicadas al desarrollo y evolución científica de la Sociología y las Ciencias Sociales se han consolidado entre ellas: asociaciones de Sociología en cada país latinoamericano, organismos y facultades especializadas (Clacso, Flacso), organismos regionales (Cepal) o asociaciones promotoras de congresos latinoamericanos y centroamericanos por Alas-Acas. 


\section{Tercera parte}

\section{Sociedad globalizada, capitalismo neoliberal y socialismo. Sociología de los nuevos tiempos}

La sociedad salvadoreña, como parte de ese contexto mundial altamente tecnologizado, va cambiando formas de pensar y actuar para abrirse al mundo global. Plantear nuevos enfoques sociológicos, aunque provenientes del eurocentrismo, se tornan útiles para comprender la globalización neoliberal que desafía a la creación de nuestros propios cuerpos teóricos e hipótesis y prácticas sociales que aporten conocimiento a la solución de nuestros problemas domésticos.

\subsection{La Sociología del futuro. Globalización y socialismo}

\section{Nuevos conceptos sociológicos para la sociedad del siglo XXI}

Las nuevas élites intelectuales del siglo XXI, herederas del pasado, continúan replicando parte de la mística del asombro, curiosidad, descubrimiento y sabiduría, como cumpliendo una ley de la evolución del pensamiento sociológico. Asumen de forma visionaria y propositiva los desafíos de la globalización neoliberal generadora de procesos antagónicos entre progreso, caos y catástrofes: a) Progreso: nuevas "eras", como la cibernética de la tecnología digital; la conquista del espacio sideral, la nanotecnología, de la información y las comunicaciones, que en conjunto van produciendo la "sociedad del conocimiento", la "Modernidad Líquida" o la "Sociedad Red". b) Caos: guerras teledirigidas poco convencionales, multicrisis sistémica: demográfica, sobrepoblación migrante, inseguridad, violencia, climática y otras que impactan y afectan la vida de la especie humana y de la naturaleza. Vivimos desenlaces del capitalismo neoliberal que manifiestan señales de crisis estructural de la civilización, que surgió hace casi cinco siglos.

Tales antagonismos forman conciencia crítica y de esperanza para que generaciones, actuales y futuras, sepan aprovechar beneficios del progreso sin caer en adicciones del consumismo mercantilista. A la vez, organizarse en nuevos movimientos populares para cuestionar y detener la deshumanización que produce la crisis y proponer la construcción de una sociedad humanizada.

La sociología ha evolucionado en medio de la polarización de dos sistemas de vida, guerras imperialistas, megamercados, políticas transnacionales y globalizadoras que producen más angustias y crisis humanitaria: climáticaecológica, demográfica-migratoria, económica/riqueza-pobreza, alimentaria, energética, de valores. Surge la necesidad de intentar redescubrir parte de aquel espíritu y de aquella visión integradora con que los padres fundadores de la Sociología (Comte...) organizaron sus cuerpos teóricos clásicos. Salir de la atomización en que cayó la Sociología, a la que Willy Soto (cf. p. 29, 37) llama 
"feudos disciplinarios, realidad seccionada", que no ha permitido aprehender acontecimientos con visión integradora.

\subsection{La "sociedad sólida" y la "sociedad líquida" de Zygmunt Bauman (*)}

Nuestra sociedad salvadoreña, como parte de ese contexto mundial globalizante y altamente tecnologizado, está sometida a los cambios en las formas de pensar y abrirse a ese mundo. Es útil plantear parte del pensamiento de dos sociólogos, quienes desde sus obras sociológicas formulan teorías con una nueva dimensión de la sociedad capitalista y socialista. Transcribimos casi textual algunos comentarios del pensamiento de Bauman.

Con nuevos enfoques teórico-metodológicos, poco usuales en la tradicional sociología y las Ciencias Sociales, Bauman plantea una nueva forma de entender la actual sociedad moderna y construye sus conceptos muy innovadores y provocativos.

a) Sociología del cambio: sociología reflexiva. Con un análisis histórico sobre la evolución de la sociedad y de la Sociología, se interesa en investigar la estratificación social, el movimiento obrero y temas más globales, tales como los cambios de la naturaleza de la modernidad. La lógica de su hipótesis es que todo cambio social, necesario y dinámico, tiende a modificar la realidad de la sociedad moderna, conceptualizada y comprendida como la relación entre la sociedad sólida (seguridad, contenidos, valores) y la sociedad líquida (movilidad, incertidumbre, relatividad de valores). Esta vía del cambio es la única posible, necesaria y oportuna para evitar los conflictos sociales y mejorar las condiciones de vida (Bauman, Wikipedia). Refiere que la nueva estética del consumo_tiende al consumismo y este a la sociedad de consumidores en la que las clases que concentran las riquezas pasan a ser objetos de adoración y los "nuevos pobres" son aquellos que son incapaces de acceder al consumo y a la novedad del sistema capitalista.

b) ¿Qué es la modernidad líquida y qué es la sociedad líquida? Retoma parte de la historia comparativa de la sociedad que se caracterizaba por el sentido de pertenencia del individuo, muy marcado entre los distintos estratos sociales.

En el siglo XVIII, y a finales del XIX los grandes cambios que experimentó la sociedad, en especial a partir de la lucha de clases, entre el proletariado y los dueños de los procesos de producción, las sociedades colectivas se han desintegrado.

(*) Zygmunt Bauman (Pozna, Polonia, 1925) sociólogo, filósofo y ensayista polaco de origen judío. Su obra comenzó en la década1950; se ocupa de las clases_sociales, el socialismo, el holocausto, la hermenéutica, la modernidad y la posmodernidad, el consumismo, la globalización y la nueva pobreza. Desarrolló el concepto de la modernidad_líquida y acuñó el término correspondiente. 
Los cambios vertiginosos de los monopolios del imperialismo comercial de finales del siglo XX han provocado la globalización en contubernio con gobiernos neoliberales. Una de las consecuencias de la modernidad, son los "desechos" que deja el crecimiento exponencial de la población mundial, $\mathrm{y}$, en este caso, son "residuos humanos" producto de las migraciones y la globalización, una consecuencia inevitable de la modernidad. Este flujo de poblaciones no se puede reabsorber; y es tan serio para diferentes partes del mundo, principalmente en países primer mundistas, como Estados Unidos, y la Unión Europea. El problema de la migración se ha convertido en uno de los principales temas de la agenda dentro del grupo que hegemoniza el planeta.

Cómo convivir con los otros ha sido un problema omnipresente de la sociedad occidental; la separación del "otro", excluyéndolo (estrategia émica); la asimilación del otro, despojándolo de su otredad (estrategia fágica), y la invisibilización del otro, para que desaparezca del propio mapa mental. La modernidad líquida es un proceso que se refiere a que el único valor heterorreferenciado es la necesidad de hacerse con una identidad flexible y versátil que haga frente a las distintas mutaciones que el sujeto ha de enfrentar a lo largo de su vida. La búsqueda de la identidad es tarea y responsabilidad vital del sujeto; y construirse a sí mismo constituye al mismo tiempo la última fuente de arraigo.

La globalización ha hecho frágiles las identidades, volubles, maleables y permeables, que ha dado paso a la individualidad en términos de ciudadanía; el individuo, para poder integrarse a una sociedad cada vez más global, tiene que pasar sin identidad fija, tiene que inventar, crear y moldear máscaras de supervivencia. Las identidades son semejantes a una costra volcánica que se endurece, vuelve a fundirse y cambia constantemente de forma. Desde una vista externa parecen estables, pero al ser miradas por el propio sujeto aparece la fragilidad y el desgarro constante. Esta identidad escurridiza nos hace cada vez más dependientes del otro, pero es ahí donde se encuentra la esperanza como una responsabilidad reflexiva que busca la autonomía del resto y la constante autorrealización y la constante inconclusión debido a la falta de un_telos en la modernidad tardía. Debe crear condiciones de crecimiento en términos de humanidad, conciencia colectiva, por el bien individual a partir del común, en copla con la naturaleza.

\subsection{La "sociedad red" de Manuel Castells (*)}

La sociedad de posmodernidad, además de globalización transnacional, es revolución de la tecnología digital satelital divulgada a través de los medios de comunicación de masas/teléfonos celulares, internet y otros artefactos que van configurado un mundo de complejas interrelaciones de fenómenos sociales a manera de una megared de distintas sociedades y culturas del planeta en la vivimos inmersos los seres humanos. ¿Cómo entender esta complejidad que desafía a élites de la Sociología? 
Castells, con un equipo de especialistas en distintos ámbitos de las ciencias sociales, explora las pautas y dinámicas de la que ha denominado la sociedad red. Desde mediados y finales del siglo XX hasta el presente, se acrecentó la influencia de la globalización económica-cultural y la revolución tecnológica digital en las comunicaciones. Es la era de las TIC (tecnologías de la información y comunicación) y las redes sociales, que han producido a escala planetaria nuevos campos de la realidad empírica.

Con base en datos estadísticos y etnográficos, resultado de investigaciones realizadas durante quince años en sociedades como China, India, Europa, Estados Unidos y América Latina, traza la historia de la revolución tecnológica digital y genética. Estudia y examina la transformación informacional, la globalización de la economía y la emergencia de una nueva cultura (Castells 2005/a). Es la nueva forma de organización social surgida en esta era de la información, que es una trilogía entre economía, sociedad y cultura (Castells, 2006-b).

La sociedad red (Castells/b) es la interacción entre tecnología y sociedad que se torna decisiva como redes de comunicación electrónicas en contextos culturales e institucionales tan distintos: en la economía, las empresas, la productividad, en los mercados mercados financieros globales, el trabajo y empleo. El uso del internet, teléfono celular, iphone y otros artefactos digitales permite que cada persona pueda tener otra concepción social del tiempo y del espacio urbano, regional y mundial, potenciando su identidad cultural, la educación, la salud, influir en el movimiento antiglobalización, en los procesos políticos, en las políticas públicas y en otras actividades de la vida cotidiana.

¿Somos la generación de familias y amigos-as que vivimos la vida cotidiana pendiente del Facebook, de las redes sociales, del teléfono celular, del internet y otros artefactos para comunicarnos virtualmente?, ¿estamos perdiendo la comunicación "cara a cara" y el calor humano para saludarnos?. La Sociología debe enfrentar estos desafíos y teorizar críticamente esta nueva forma de vida digital que tiende a deshumanizarnos cuando más necesitamos la solidaridad humana.

\section{Una breve conclusión}

Este breve recorrido parcial y limitado permite darnos cuenta de que la Sociología forjadora de un pensamiento racional, que surgió en medio de avatares de grandes acontecimientos transformadores de la civilización capitalista, aún continúa en pleno siglo XXI. La caótica sociedad industrial capitalista liberal

(*) Profesor de la Universitat Oberta de Catalunya, ocupa la cátedra Wallis Annenberg de Tecnología de la Comunicación y Sociedad; Universidad de California del Sur. Catedrático emérito de Sociología y Planificación Urbana y Regional; Universidad de California/Berkeley y profesor visitante de Ciencia, Tecnología y Sociedad del MIT. 
surgió ya polarizada entre poderes, autoritarismos, hegemonías y dominación, y continúa en el neoliberalismo global.

Los nuevos tiempos del siglo XXI y del tercer milenio nos plantean grandes desafíos, que nos hacen sentir que nos aproximamos cada vez más a una crisis de civilización de la sociedad humana. Los desafíos siempre han estado presentes, sin embargo la esperanza de la especie humana es alcanzar un creciente bienestar generalizado, superando estos avatares en algún tramo de la historia que se debe construir.

Surgen los siguientes interrogantes, que nos desafían:

¿Qué tan distante estamos de aquel pensamiento racional que se consolidó en la sociedad del siglo XIX europeo?, ¿qué tan conscientes estamos viviendo el mundo virtual posmoderno (internet, celular...) que produce un pensamiento "liquido", fugaz e intemporal impuesto por la era digital y por la "sociedad red"?, ¿a qué ritmo se desnaturaliza, volatiliza y perdemos nuestra identidad individual y societal?

Desde mediados del siglo Octavio Paz, en 1959, época de la Guerra Fría (en la segunda posguerra mundial), escribía:

tenemos que aprender a mirar cara a cara la realidad. Inventar si es necesario palabras nuevas e ideas nuevas para estas nuevas y extrañas realidades que nos han salido al paso. Pensar es el primer deber de la intelligentsia. $\mathrm{Y}$ en ciertos casos el único.

En los años 90, I. Wallerstein señalaba que:

es posible que estemos presenciando el fin de un tipo de racionalidad que ya no es apropiada con la ciencia, la ética o los sistemas sociales en un presente de cuestionamiento considerable...; además ahora existe una racionalidad tecnocrática... como la versión más avanzada del racionalismo moderno... como un avatar del darwinismo social (Wallerstein: 8).

Élites de distintas formas de pensamiento de presentes y futuras generaciones tendrán que aprender a pensar y construir, en la práctica cotidiana, la Sociología, las Ciencias Sociales y las Ciencias Naturales que necesita la sociedad del siglo XXI. Ese es el mayor desafío.

Reiteramos la frase: "Las CCSS del siglo XXI están por hacerse" (Scribano, pág. 422). 


\section{Referentes bibliográficos}

Álvarez, Uría, Fernando (2007), Karl Marx, Max Weber y Emilio Durkheim, Sociología y Educación. Textos e intervenciones de los sociólogos clásicos, Ediciones Morata, Madrid, España.

Bourdieu, Pierre, "La Sociología: ¿Es una ciencia?”, en www.memoria.com. $\mathrm{mx} / 158 /$ bourdieu.htm

Castells, Manuel (2005-a), La era de la información (vol.1): Economía, Sociedad y Cultura. La sociedad red, Alianza Editorial, España, en: http:// www.casadellibro.com/libro-la-era-de-la-informacion-voll-economia-sociedad-y- cultura-la-sociedad-red/9788420677002/1030171

Castells, Manuel (2006-b), La sociedad red, Alianza Editorial, España, en: http:// www.casadellibro.com/libro-la-sociedad-red/9788420647845/1101018

Elías, Norbert (2006), Sociología Fundamental, Editorial, Gedisa, Primera reimpresión, Barcelona, España.

Giddens, Anthony (1994), Sociología, 2a . Edición, Alianza Editorial, Madrid, España.

Gurvitch, Georges (1971), Dialéctica y Sociología, 2a ${ }^{\mathrm{a}}$. Edición, Alianza Editorial, Madrid, España.

Kon, I (redactor, S.F.), Historia de la Sociología del siglo XIX, Comienzos del $X X$, Editorial Progreso, Moscú, URSS.

"Obra y pensamiento de Zygmunt Bauman", en https://es.wikipedia.org/wiki/ Zygmunt Bauman

Parsons, Talcot /a, (compilador-1969), La sociología norteamericana contemporánea (perspectivas, problemas y métodos), editorial Paidós, Argentina.

Parsons, T /b, (1968), Hacia una teoría general de la Acción, Editorial Kapelusz, Buenos Aires, Argentina.

Raison, Timothy (1970), Los padres fundadores de la ciencia social, Editorial Anagrama, Barcelona, España.

Ritzer, George (1994), Teoría Sociológica Contemporánea, McGraw-Hill Editores -2 tomos, México, D.F.

Simmel, George (2012), Cuestiones fundamentales de sociología, Gedisa Editorial, $2^{\mathrm{a}}$. edición, Barcelona, España.

"Sociología: principales autores y evolución histórica", en http://www.taringa. net/posts/ciencia- educacion/14240931/sociologia-principales-autores-yevolucion-historica.html

Soto Acosta, Willy y Morales Camacho, María Fernanda (2015), "Tendencias de Investigación en Ciencias Sociales en América Latina", en: Ciencias Sociales y Relaciones Internacionales: Nuevas Perspectivas desde América Latina, Escuela de Relaciones Internacionales, Universidad NacionalUNA, Costa Rica-Clacso.

Scribano, Adrián (2015), "Metodología de la Investigación Social en el siglo XXI: Notas sobre algunos desafíos", en: Ciencias Sociales y Relaciones Internacionales: Nuevas Perspectivas desde América Latina, Escuela de RR II, Universidad Nacional-UNA, Costa Rica-Clacso. 
Spencer, Herbert (1942), La Ciencia Social, Editorial Tor, Buenos Aires, Argentina.

Timasheff, Nicolas S. (1983), La Teoría Sociológica, décima reimpresión, Fondo de Cultura Económica, México D.F.

Torres Rivas, Edelberto (1993), "Curso de actualización de la Teoría Social:

El pensamiento teórico-clásico de Marx, Durkheim y Weber", Facultad

Latinoamericana de Ciencias Sociales (Flacso), -impresión-, El Salvador Vargas-Mendoza, J. E. (2007), "Sociología: 10 grandes pensadores". México: Asociación Oaxaqueña- Psicología, en http://www.conductitlan.net/sociologos.ppt

Wallerstein, Inmanuel (1996), Abrir las Ciencias Sociales, Siglo XXI Editores, México. 


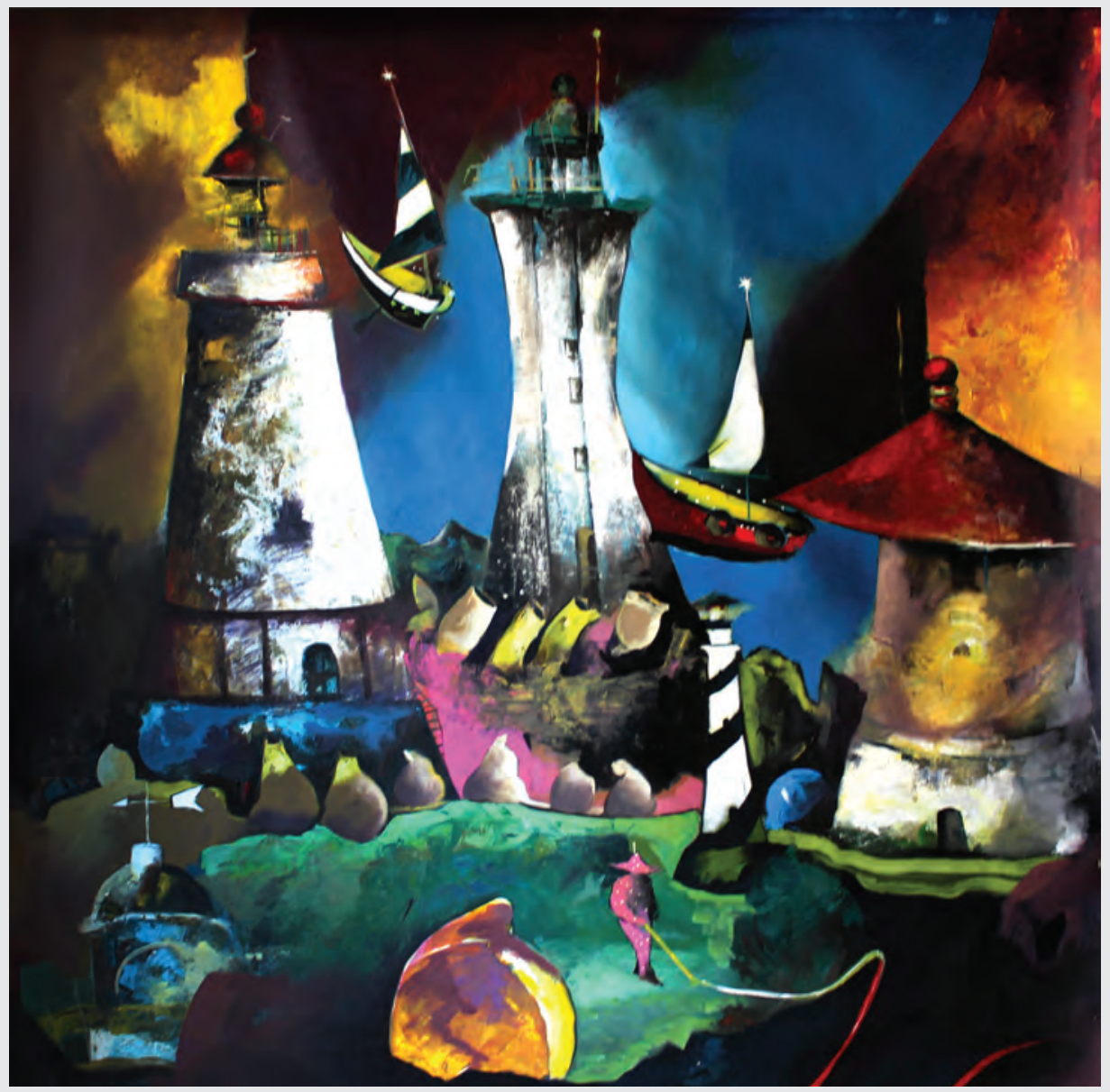

\section{"La ciudad faro"}

Medidas: 144 x $152.5 \mathrm{cms}$

Técnica: mixta

Año: 2009 